\title{
Perceptions of EFL College Students toward Collaborative Learning
}

\author{
Yingling $\mathrm{Chen}^{1}$ \\ ${ }^{1}$ Center for General Education, Orieantal Institute of Technology, New Taipei City, Taiwan \\ Correspondence: Yingling Chen, Center for General Education, Oriental Instutte of Technology, New Taipei \\ City, Taiwan. Tel: 886-909-301-288. E-mail: ci10226@mail.oit.edu.tw
}

Received: October 27, 2017 Accepted: December 13, 2017 Online Published: December 15, 2017

doi: 10.5539/elt.v11n2p1

URL: http://doi.org/10.5539/elt.v11n2p1

\begin{abstract}
The purpose of the study was to understand the perceptions of EFL college students toward collaborative learning (CL). This qualitative research design used narrative approach since the study emphasized on each participant's learning experiences with CL strategy. The data collection instruments for this research were consisted by interview questions. The researcher observed, took notes, and recorded Interview responses from each participant in order to understand their perceptions of collaborative learning. The finding of this study provides inspirations and motivation for English teachers to offer second language learners suitable curriculum and environment. Through collaborative learning, the results show that students quickly realize that they are able to solve problems as a group that they would not be able to solve as individuals. Students were satisfied by peer coaching, and peer review. Students worked together and brought effective strategies into the classroom activity.
\end{abstract}

Keywords: collaborative learning, EFL, perceptions

\section{Introduction}

English as a foreign language has become an obligation in Taiwan. Many students learn English for passing school entrance exam; they will never discover the joy of learning in their daily life. Brown (2007) stated sociolinguistics claimed that learners should have knowledge to understand and produce sentences that are not only grammatically correct but also are appropriate in social contexts.

Collaborative Learning focuses on using small, cooperative groups in education which helps educators improve learning in their classes. Teachers encourage classroom collaboration by assigning students to groups to review their homework, do daily class worksheets, participate in moderated discussions, and complete hands-on activities. Nayan, Shafie, Mansor, Maesin, and Osman (2010) stated that collaboration can be applied in teaching and learning process as it enables students to be actively involved in the process and when they do so, they can better understand certain concepts or retain knowledge in their long-term memory. In addition, students apply their acquired knowledge practically when teachers' value of virtual teaching connected and worked with the real world. Students' personal experiences and prior knowledge help acquiring and producing comprehension in the collaborative classroom. Hence, understanding EFL students' perceptions of collaborative learning is an efficient path for language teachers not only offering a suitable curriculum and environment but also developing academic progress.

\subsection{Literature Review}

\subsubsection{Collaborative Language Teaching and Learning}

Collaboration means sharing ideas, cooperating with team members, and working on the same project. If students learn collaboratively, they will experience lively and successful learning process and teachers can produce students with strong academic performance (Brown, 2008). Therefore, Collaborative language teaching activities can promote second language learners' academic progress, problem solving skills, and learning motivation. Second language learners' have the opportunities to perform better and use their logical thinking abilities (Wentzel \& Wakins, 2002). Students will be more engaged in the language classroom and carry out more positive learning outcomes while the instructor uses collaborative language teaching strategy to help students acquire the second language. A Teacher's strategy use in the language classroom influences second language learners' achievement. Bernaus and Gardner (2008) claimed that the more controlling the teacher seemed to the students, the less autonomy they felt, and also the more informative the teacher was perceived to be in terms of the feedback given, the more competent the students felt. Students at all levels and various 
learning characteristics have better chances to receive needs and be educated effectively with teacher's collaborative instruction. Therefore, Students have more opportunities to practice their problem-solving strategies, communication and social skills

Collaborative teaching and learning play important roles in improving students' learning. Osman, Nayan, Mansor, Maesin, and Shafie presented that collaboration means to practice in a safe environment which is made up of an accepting and diverse group of people who have a common interest or issue and these people need to make discoveries or find possible solutions to tasks given. When students work collaboratively, second language learners have chances to enhance their oral skills and experience conflict on goals and tasks. Students share and explore their knowledge and ideas with the rest of the classmates. For some shy students, collaborative learning encourages them to express their opinions, creates more opportunities for them to expose to second language environment, and helps them to increase classroom participation. Benjamin (2000) stated that students learning outcomes improved when teaching and learning are reflective and collaborative. Ahlstrom (2003) stated that students and teacher should engage in dialogue, investigating themes as equals and creating new understanding of the world together. Real-life material helps teachers to figure out and address students' needs, reflect collaboration between the learners and the teachers, and indirectly include regular evaluation by observing students' performances in the classroom. When teachers have the freedom and eagerness to try new things and strategies in the material and activity of language classrooms, students can profit from the creation and develop new knowledge in a practical way. Ocker and Yaverbaum (2002) presented that numerous studies have been carried out on collaborative learning and many have shown that when students were given the opportunity to work collaboratively, they were able to perform better.

Studies have looked at students learn collaboratively, they will experience lively and successful learning process and teachers can produce students with strong academic performance (Brown, 2008).

\subsubsection{Peer Coaching}

Peer coaching provides teachers opportunities to share ideas, to strengthen their teaching skills, encourage one another to create a better learning environment for their students, and develop a functional school system in order to meet all kinds of challenges from government policies, parents' involvements, and students' learning difficulties. Peyton Farrell Buzbee (2005) stated that when peer coaching is used in conjunction with collaborative teaching, it enhances teacher improvement and students learning by providing ongoing opportunities for educators to share their unique knowledge bases and expertise, allowing exploration of new ideas and expansion of professional skill repertoires. Recognizing and respecting linguistically and culturally diversity helps teachers and learners to create flexible schedule for collaborative activities. Support and facilitate individual needs by valuing students' culture background. Perez (2004) stated schools, acting as agents for the culture, control the extent to which personal knowledge may enter into the public knowledge of school curriculum. In other words, students are able to increase their participation by sharing a personal cultural context through teachers' collaborative instruction.

Second language learners use their prior knowledge to decode and encode knowledge. Students are also able to develop new cultural and social information in the practice because they come from different family and educational background. Students have various levels of intelligences and produce distinct thinking. Peer coaching supports collaborative teaching; in other words, collaborative teaching also supports peer coaching. When effectively using peer coaching, it helps teachers to identify the area of teaching which they want to improve and develop. Bowman and McCormick (2000) presented that peer coaching provides opportunities to refine reaching skills through immediate feedback and through experimentations with alternate strategies as a result of the informal evaluation.

\section{Methodology}

The study was undertaken by interviewing respondents with open questions.

This qualitative research design used narrative approach since the study emphasized on each participant's learning experience or story sharing. Fifteen Taiwanese college students were selected from the north part of Taiwan. Ten of the respondents were female and five of them were male. Seven participants were in a suburban area, and the others were in a metropolitan area. They are now full-time students enrolled in three different universities. The qualitative research was collected by doing interviews. The data collection was though phone interview and face to face interview, as well as email connection and on-line communication. Each interview took 30-45 minutes for four weeks. The researcher met with the participants once a week. The researcher observed, took notes, and recorded Interview responses from each participant in order to understand their perceptions of collaborative learning. 
The research specific the most important point from the interview questions that the participants answer in the research project. Each respondent signed a consent form before the interview was undertaken. During the interview, the researcher took notes and recorded interview conversations for observing individual differences.

Being neutral is necessary while collecting the data in order to prevent misconduct and impropriety. The researcher analyzed qualitative data from observation, note taking, and interview. Analysis techniques were used such as coding the data, assigning labels to code, comparing and contrasting data. The researcher used her own words to described each participants' answers and experiences by compared and contrasted the differences and similarities of participants' interview responses. Creswell (2009) claimed that researchers need to protect their research participants. Therefore, data did not provide any identifiable information. Each participant has a pseudonym for protecting the privacy and confidentiality. After observing, recording, conducting interview, and analyzing the data, the researchers send the participants the results by emails in order to make sure the information is conducted accurately from each respondent.

\section{Findings}

\subsection{Research Question}

What are Taiwanese college students' perception about collaborative learning?

Most of the participants stated that they had positive learning experiences through collaborative learning strategy. Students were asked to watch a short film of scenario, then join the question discussion and critique. During the CL activity, the instructor assisted each group and provided directions for the discussion. Students helped each other as a group. One participant stated that "CL was really working on me"; he further explained that he learns better especially with the instructor's support and monitoring. In other words, the more support and monitoring of the group work by the instructor, the more positive attitude students gained from CL. The students were satisfied with the planning and monitoring process used in cooperative EFL learning. 12 participants believed that group tasks develop their thinking more than individual learning. CL makes learning interactive compare to the traditional learning environment, it provides interesting and social connection between peers and instructors. Students also expressed that during the assigned work, they felt responsibility of work, committed to accomplishment of each member and their group. They were afraid of losing face by bad performances. Overall the findings reflect to most of the studies which showed that the importance of collaborative learning includes (1) collaborative learning helps not only students in learning but also assist teachers in improving teaching skills by interacting with students during classroom lecture. (2) Students' participation plays important roles in second language learning. In addition, (3) teachers can develop a supportive learning environment and motivate students learn and produce their effective second language. Most of the participants stated that learning how to work in teams in the EFL classroom made the assignments or tasks easier as all the work is done in groups". 2 students wrote "I become more outgoing and my interpersonal skills are developed, I am not afraid of speaking English and express my opinion". 3 participants stated that CL strategy facilitated my learning and helped me catch up with others and made me more productive compare to the past". Numerous studies have been carried out on collaborative learning and many have shown that when students were given the opportunity to work collaboratively, they were able to perform better (Ocker \& Yaverbaum, 2001; Brown, 2008).

\section{Conclusion}

Through collaborative learning, the results show that students quickly realize that they are able to solve problems as a group that they would not be able to solve as individuals. Students are able to be trained to collaborate with each other and to give feedback on each other's work. Students were satisfied by peer coaching, and peer review. Students worked together and brought effective strategies into the classroom activity. When language teachers help students learn collaboratively, they have more chances to understand students' needs and know how to assist their students' learning. Teachers' facilitation and students' participation expand students' logical thinking, social network and communicative skills. Peers act as a private tutor during the collaborative a

\section{References}

Ahlstrom, C. (2003). Collaborating with students to build curriculum that incorporates real life material. Focus on basics, connecting, research, and practice, Issue C. Volume 6, 2003. Retrieved from World Education

Benjamin, J. (2000). The scholarship of teaching in teams: What does it look like in practice? Higher Education Research and Development, 19, 191-204. https://doi.org/10.1080/072943600445646

Bernaus, M., \& Gardner, R. (2008). Teacher Motivation Strategies, Student Perceptions, Student Motivation, and English Achievement. Modern Language Journal, 92(3), 387-401. https://doi.org/10.1111/j.1540-4781.2008.00753.x 
Bowman, C. L., \& McCormick, S. (2000). Comparison of peer coaching versus traditional supervision effects. Journal of Educational Research, 93(4), 256-261. https://doi.org/10.1080/00220670009598714

Brown, H. D. (2007). Principles of language learning and teaching. New York: Pearson Education, Inc.

Brown, F. A. (2008). Collaborative learning in the EAP classroom: Students' perceptions. English for specific purpose, 1(17).

Creswell, J.W. (3rd ed.) (2009). Research design: Qualitative, quantitative, and missed methods approaches. CA: SAGE Publications, Inc

Nayan, S., Shafie, L., Mansor, M., Maesin, A., \& Osman, N. (2010). The Practice of Collaborative Learning among Lecturers in Malaysia. Management Science \& Engineering, 4(2), 115-123.

Ocker, R. J., \& Yaverbaum, G. J. (Winter 2002). Collaborative learning environments: exploring student attitudes and satisfaction in face-to-face and synchronous.

Osman, N., Nayan, S., Mansor, M., Maesin, A., \& Shafie, L. (2010). Spoken Skills, Communication Apprehension and Collaborative Learning. Cross-Cultural Communication, 6(2), 117-124.

Peyton Farrell Buzbee, L. (2005). Peer coaching as a support to collaborative teaching. Mentoring \& Tutoring: Partnership in Learning, 13(1), 83-94. https://doi.org/10.1080/13611260500040351

Perez, B. (2nd ed.). (2004). Sociocultural contexts of language and literacy. Mahwah, NJ: Lawrence Erlbaum Associates.

Wenzel, K.R., \& Watkins, D. E. (2002). Peer relationship and collaborative learning as contexts for academic enablers. School Psychology Review, 31(3), 366.

\section{Copyrights}

Copyright for this article is retained by the author(s), with first publication rights granted to the journal.

This is an open-access article distributed under the terms and conditions of the Creative Commons Attribution license (http://creativecommons.org/licenses/by/4.0/). 